closed. From that day to this the cyst has not enlarged; indeed, it underwent some degree of diminution. I have seen the patient at intervals of a few months since and she has continued very comfortable and able to attend to her business. During the time I had the patient under observation previously to the operation the cyst had been increasing, and I only decided to operate because of the disturbance and pain it was causing in its neighbourhood, as well as rendering the woman unfit for her duties and giving her great general discomfort. Its presence does not now cause these symptoms in anything like the same degree, and, as I have already said, she attends to her daily duties, which are of an arduous kind. Why the cyst ceased to increase is another question, but it may have been in some measure due to the fact that I made her rest absolutely for six months.

I accidentally discovered a cyst of the ovary when attending a woman four years ago for another matter. It had not increased when I last attended her a few months ago, and she at present suffers only a little from it. She does not know of its existence. Why should she so long as it gives such slight trouble and she is quite able for her duties? She has had two children since I discovered the cyst, and if it has remained in statu quo for four years (and perhaps for four years previously to that) may it not remain so for four, or even fourteen, more? I may also instance the case of a young married woman in whom a tumour (cystic) of one ovary has exi-ted to my knowledge for years. It has at times caused a good deal of suffering, and on one occasion I almost decided to remove it. Several months of absolute rest, however, with some treatment, helped her greatly, and she has been able to attend to her household affairs with a considerably greater degree of comfort than previously. I have known of the existence of this cyst for six or seven years, and it does not increase.

These, possibly it may be advanced, are not instances quite analogous, except the first, to those mentioned by Mr. Clement Lucas, inasmuch as in his the abdomen was opened, and the advocates for removal would say that it would be better to remove the organ then than for the woman to undergo the trouble, anxiety, and suffering of a second operation, with its consequent risk and expense. The risk, of course, is small now, thanks to the progress made in surgery during the last quarter of a century. But there is risk, and it ought to be avoided, to say nothing of the other concomitants of an operation. But if there is a reasonable hope that the ovary may not get worse or may recover, I think the woman, especially if a young one, ought to have a chance and the ovary should be left, and I think it may be fairly said that the cases cited show that ovaries to some extent diseased may be left sometimes with a very fair prospect that they may not only not cause increased trouble in the future, but that they may remain stationary or even recover. If, then, some diseased conditions of the ovaries remain quiescent for years, improve, and even get well, we ought not too hastily to conclude that operative interference is necessary, but should keep our patients under observation and treatment. I am confident that some operations may be avoided by this plan, and the subjects of the disease be enabled to pursue their daily duties with comfort. If the time comes for operation the case can be dealt with then just as well as earlier, provided one does not allow it to go too far until dangerous complications arise. I am quite alive to the necessity for early operation. I am sure, however we will lose nothing by waiting and watching, selecting the proper cases for such a course.

$$
\text { I am, Sirs, yours truly, }
$$

Lowndes-street, S.W., May 4th, 1897

$$
\text { D. THOMson, M.D. Glasg. }
$$

\section{TUBERCULOSIS IN DAIRY CATTLE.}

\section{To the Editors of THE LANCET.}

SIRs, - In the issue of THE LANCET of May 1st your Irish correspondent refers to the resolution passed by the Dublin University Biological Association concerning the prevalence of tuberculosis among dairy cattle. He further states that it is reassuring to find in the report of the Cowkeepers' Association that the result of a veterinary examination by two gentlemen shows only 4 cows out of 1500 examined were affected with tuberculosis. There are some considerations which would lead one to place very small reliance on the results obtained by these gentlemen, to which I wish to draw public attention.

From a return furnished to me by the Veterinary Department of the Privy Council Office, Ireland, I take the following statement: "It appears from the departmental records that the post-mortem examination of the lungs of cattle slaughtered by direction of the Veterinary Department between the years 1888-1893 in the North and South Dublin Unions as having been in contact with cattle affected with pleuro-pneumonia, or otherwise exposed to the infection of that disease, showed that the proportion of cases in which the lungs were affected with tuberculosis was almost 5 per cent. The majority of cattle slaughtered were dairy cows." It is evident from this statement that if only four out of 1500 cows are now affected with tuberculosis there must be a most marked improvement in the health of cattle in this district. Indeed, such a marked change in so short a time is sufficiently remarkable to call for some explanation. So far from any explanation of this improvement being forthcoming it is a matter of common knowledge that little or nothing is being, or has been, done to improve the state of the dairy yards, the unsanitary condition of which has been so often pointed out. Taking these facts into consideration, and remembering that the extraordinary prevalence of tuberculosis among dairy cattle in general has been amply proved by numerous statistics, we shall, I think. be justified in doubting these results so long as the methods by which they were obtained are open to suspicion. Professor McFadyean, when summing up the results of his experiments for the recent Royal Commission, states: "The conclusion that appears warranted is that ordinary clinical examination is almost valueless for the detection of tuberculosis in its carly stages." Over and over again in his published works this great authority on veterinary pathology has stated that ordinary clinical examination even in the hands of the most skilled and experienced veterinary surgeons is incapable of pointing out all the animals affected with tuberculosis. Unless some more accurate means of diagnosis is used than ordinary clinical examination affords veterinary surgeons merely leave themselves open to the charge of incompetence by certifying animals to be free from tuberculosis. It would appear that Koch's tuberculin in the hands of skilled surgeons is the most accurate method of diagnosing tuberculosis of cattle, and where it cannot be used most veterinary surgeons decline to express a decided opinion. We cannot, then, accept any statement as to the number of tuberculous cattle in our dairy yards which is not based on examination with tuberculin or the results of post-mortem examination. Was this test employed by the inspectors who reported to the Cowkeepers Association? If so, where are the tabulated returns of the cattle examined? The answer is, I think, that these returns do not exist, because the method was not used, and in consequence the report is valueless.

I am, Sirs, yours faithfully,

Dublin, May 4th, 1897

T. Percy C. KIRKPATRICK, M.D. Dub.

\section{"THE SWEDISH SYSTEM OF PHYSICAL EDUCATION."}

To the Editors of THE LANCET.

SIRs,-If you would kindly allow me space in your next issue I should be glad to efface an impression which I regret. to have made. In your review of my booklet on the above subject exception is taken to one observation. Your reviewer writes: "The English medical profession is charged with "insular prejudice against anything branded as foreign." I Reference was here intended to the British nation as a whole. As a general and national characteristic: it would be difficult to deny that John Bull entertains a certain scorn for the foreigner and for what is foreign, and has an ingrained belief in the superiority of himself and his. opinions. This remark, however, was not specially directed against the medical profession; for does she not gracefully acknowledge that many of the brightest jewels in her crown have been set there by other than English hands? In proceeding I have ventured to state that that learned body" is characterised by a conservative spirit, but between "conservative spirit" and "insular prejudice" exists a distinction which certainly constitutes a difference.

Believe me, Sirs, yours very truly,

Bristol, May 4th, 1897

THEODORA JOHNSON. 